\title{
MSPD Sample Preparation Approach for Reversed-Phase Liquid Chromatographic Analysis of Pesticide Residues in Stem of Coconut Palm
}

\author{
Jordana Alves Ferreira • Luís Fabrício Santana Santos • Nicaellen Roberta da Silva Souza • \\ Sandro Navickiene $\cdot$ Frederico Alberto de Oliveira $\cdot$ Viviane Talamini
}

Received: 19 November 2012/Accepted: 21 May 2013/Published online: 31 May 2013

(C) Springer Science+Business Media New York 2013

\begin{abstract}
A method was developed using matrix solidphase dispersion, together with liquid chromatography with ultraviolet diode array detector for determination of carbofuran, difenoconazole, $\beta$-cyfluthrin, spirodiclofen and thiophanate-methyl in stem of coconut palm. The best results were obtained using $2.0 \mathrm{~g}$ of stem, $1.6 \mathrm{~g}$ of Florisil as sorbent and cyclohexane:acetone mixture (4:1). The method was validated using stem samples spiked with pesticides at four concentration levels $(0.05-2.0 \mu \mathrm{g} / \mathrm{g})$. Average recoveries ranged from $70 \%$ to $114.3 \%$, with relative standard deviations between $1.2 \%$ and $19.2 \%$. Detection and quantification limits were in the ranges $0.02-0.03$ and $0.05-0.1 \mu \mathrm{g} / \mathrm{g}$, respectively.
\end{abstract}

Keywords Cocos nucifera - Liquid chromatography · Matrix solid-phase dispersion · Pesticides · Stem

Coconut palm (Cocos nucifera Linn.) is a perennial oil seed crop with high commercial value. This palm has a pivotal role in domestic, industrial, constructional, medicinal and religious purposes. Numerous insect pests infest the coconut palm at all stages of its growth (Mohan et al. 2010). Approximately 184 insects have been recorded, excluding those infesting copra, only a few are key pests of perennial importance. Systemic insecticides injected into

J. A. Ferreira - L. F. S. Santos · N. R. da S. Souza •

S. Navickiene $(\square)$

Departamento de Química, Universidade Federal de Sergipe, Av.

Marechal Rondon s/n, São Cristóvão, SE 49100-000, Brazil

e-mail:sandnavi@ufs.br

F. A. de Oliveira $\cdot$ V. Talamini

Embrapa Tabuleiros Costeiros, Av. Beira Mar, no 3250, Aracaju, SE 49025-040, Brazil tree trunks work by absorbing into the tree's vascular system and repelling pests from the inside out. This type of insecticide can be used against a wide range of pests, including borers, aphids, leaf miners, whiteflies, thrips, and soft-scale insects (Fontes et al. 2009). Different products, like carbofuran, difenoconazole, $\beta$-cyfluthrin, spirodiclofen and thiophanate-methyl, are used to control phytophagous insects and fungal pathogens on a variety of crops in the northeastern part of Brazil. To our best knowledge, none of the papers published to date have reported the simultaneous analysis of chemical classes such as carbamate, triazole, benzimidazole, tetronic acid and pyrethroid in stem of coconut palm.

The pesticides translocation and/or distribution in plant tissues are manipulated by the pesticide physical properties such as solubility partitioning and polarity as well as the appropriate application position (Al-Samarrie and Akela 2011). Previously, monocrotophos residue levels were investigated in kernel and nut water injected in coconut palm (Ranasinghe et al. 2003). The evaluation of trunk injection technique to control grapevine wood diseases using difenoconazole was monitored (Lecomte and Darrieutort 2007), while the efficacy of eight fungicides applied via microcapsule trunk injection against the foliar pathogens apple scab (Venturia inaequalis) and powdery mildew (Phyllactinia sp.) was evaluated. Of the fungicides tested, carbendazim, the major product of degradation of thiophanate-methyl, significantly reduced disease severity (Percival and Boyle 2005).

The matrix solid-phase dispersion (MSPD) technique was developed by Barker in 1989. It has advantages over conventional techniques because it employs small amounts of sample and solvent, and the extraction procedure consists of only a few experimental steps. MSPD evolved from the solid-phase extraction (SPE) technique, modified for 
application to solid and semi-solid matrices (Garcia-Lopes et al. 2008). The MSPD procedure is based on the use of a sorbent, which acts as an abrasive in order to produce a modified "opening" of the solid matrix, facilitating the extraction process when using a suitable solvent for eluting the analytes (Barker 2007). Use of MSPD for pesticide recovery depends on the solubility of the pesticide in the eluting solvent, as well as the interactions between the matrix components, sorbent and eluent (Capriotti et al. 2010; Aquino and Navickiene 2009).

Due to the lack of literature reports concerning the use of MSPD as an extraction technique for pesticides belonging to different chemical classes from stem matrix, this paper presents an MSPD method for determination of residues of pesticides in stem of coconut palm, considering five different chemical classes, namely carbamate (carbofuran), triazole (difenoconazole), pyrethroid ( $\beta$-cyfluthrin), tetronic acid (spirodiclofen) and benzimidazole (thiophanate-methyl), with analysis by liquid chromatography with ultraviolet diode array detector (HPLC/UV-DAD).

\section{Materials and Methods}

Certified standards of carbofuran, thiophanate-methyl, difenoconazole, spirodiclofen and $\beta$-cyfluthrin were purchased from Dr. Ehrenstorfer (Augsburg, Germany). All standards were at least $97 \%$ purity. HPLC grade solvents, cyclohexane, acetone, dichloromethane and acetonitrile, were purchased from Tedia (Fairfield, OH, USA). Ultrapure grade LC water was obtained by purification of distilled water through a Milli-Q gradient system (Millipore, Bedford, MA, USA). Silica gel 60 and Florisil (70-230 mesh) from Merck (Darmstadt, Germany), neutral alumina (70-290 mesh, activity I) from Macherey-Nagel (Düren, Germany), $\mathrm{C}_{18}$-bonded silica $(50 \mu \mathrm{m})$ from Phenomenex (Torrance, CA, USA). Chemicals were used as received and without further purification.

The individual standard stock solutions of the pesticides were prepared in acetonitrile at $500 \mu \mathrm{g} \mathrm{mL}^{-1}$ and stored at $-18^{\circ} \mathrm{C}$. The working standard solutions were prepared at various concentrations by diluting the stock solutions as required in acetonitrile. These standards were used to prepare matrix-matched standard solutions. An aliquot of the stem extract was transferred to a vial and dried under a gentle nitrogen stream. Then, an appropriate volume of standard mixture, prepared in acetonitrile as describe before, was added to the vial and stirred (in a vortex) to reconstitute the extract.

Stem samples were obtained from coconut grove at the city of Aracaju (State of Sergipe, Northeast region of Brazil) owned by Embrapa-Tabuleiros Costeiros on the coconut (Cocos nucifera L.) cultivar. An amount of $400 \mathrm{~g}$ of the stem of the coconut palm was collected using a sharp knife at one meter above the ground, and they were stored in plastic bags. In the laboratory, it was dried at room temperature for 1 week, and then were powdered by a cutting mill (Wiley type), sieved, and then stored in screw cap vials. Recovery experiments were performed using $2.0 \mathrm{~g}$ portions of stem sample spiked with $500 \mu \mathrm{L}$ of working solution, resulting in concentrations of $0.05,0.5$, 1.0 and $2.0 \mu \mathrm{g} / \mathrm{g}$. The spiked samples were allowed to rest for $30 \mathrm{~min}$ to aid solvent evaporation and interaction between analytes and sample matrix. Four replicates were analyzed at each fortification level.

Two grams of stem were weighed out, and homogenized with $1.6 \mathrm{~g}$ of Florisil for $3 \mathrm{~min}$. The homogenized sample was transferred to an MSPD column consisting of a $20 \mathrm{~mL}$ capacity polyethylene syringe containing silanized glass wool (as a support base). The elution was performed under vacuum with $20 \mathrm{~mL}$ of cyclohexane:acetone $(4: 1, \mathrm{v} / \mathrm{v})$. The eluent was collected into a conical tube and concentrated to a volume of $1 \mathrm{~mL}$, using first a rotary vacuum evaporator $\left(40^{\circ} \mathrm{C}\right)$, followed by a gentle flow of nitrogen. To make extracts injectable into the LC column, they were filtered through a Nylon filter (pore size $0.45-\mu \mathrm{m}, 4-\mathrm{mm}$ id.; Sartorius, Germany). Finally, a $20 \mu \mathrm{L}$ portion of the extract was then directly analyzed by HPLC/UV-DAD.

The separation of the pesticides residues from the MSPD stem extracts was carried out using a high-performance liquid chromatography system (Shimadzu, Kyoto, Japan) equipped with a binary solvent pump (LC-20AT), DGU-20A 3 degasser, Sil-20A autosampler with volume injection set as $20 \mu \mathrm{L}$ and SPD-M20A UV diode array detector (DAD). Data acquisition and processing were performed with the LC Solution Ver. 2.0 Workstation. The chromatographic separation was performed on a reversedphase Synergy Polar-RP analytical column $(250 \times 4.6 \mathrm{~mm}$ id, $4 \mu \mathrm{m}$ particle size), protected by a security-guard cartridge Polar-RP $(4 \times 3 \mathrm{~mm}$ id), both from Phenomenex (Torrance, CA, USA). Mobile phases A and B were water and acetonitrile, respectively, delivered at a flow rate of $0.8 \mathrm{~mL} / \mathrm{min}$ at ambient temperature. The chromatographic method held the initial mobile-phase composition (90\% B) constant for $5 \mathrm{~min}$, followed by a linear gradient to $60 \% \mathrm{~B}$ at $35 \mathrm{~min}$ and back to the initial conditions in $15 \mathrm{~min}$. Spectral data from all peaks were accumulated in the range 190-800 nm and UV-Vis chromatograms were recorded at $210 \mathrm{~nm}$. By following the procedure described below, the guard column was replaced with a new one after more than about 60 injections of stem extracts. The identification of compounds in stem samples was carried out by comparing the characteristics of DAD spectra and retention time of standard compounds.

Method validation ensures analysis credibility. In this study, the parameters accuracy, precision, linearity, 
detection limit and quantification limit were considered (Bliesner 2006). The accuracy of the method was determined by recovery tests, using samples spiked at concentration levels of $0.05,0.5,1.0$ and $2.0 \mu \mathrm{g} / \mathrm{g}$. Linearity was assessed (in triplicate) by preparation of analytical curves using analytical standards prepared in blank matrix extract at concentration levels of 0.04, 0.1, 0.2, 0.4, 1.0, 2.0, 10, 15 and $20 \mu \mathrm{g} / \mathrm{mL}$. The limits of detection were calculated considering the standard deviation of the noise (a value of 7 times the standard deviation of the blank) divided by the slope of the regression line. The limits of quantification were determined as the concentration giving a response of ten times the average of the baseline noise obtained from seven unfortified samples (SANCO 2012).

\section{Results and Discussion}

Preliminary separation of the pesticides was conducted on conventional Microsorb-MV100 $\mathrm{C}_{18}(250 \mathrm{~mm} \times 4.6 \mathrm{~mm}$, $5 \mu \mathrm{m})$ and Microsorb-MV100 $\mathrm{C}_{8}(250 \mathrm{~mm} \times 4.6 \mathrm{~mm}$, $5 \mu \mathrm{m}$ ) columns supplied by Agilent Technologies (Santa Clara, CA, USA) with isocratic method. The acetonitrilewater mixture was used as mobile phase. The acetonitrilewater isocratic elution $(65: 35$, v/v) was evaluated. However, results obtained showed that the isocratic method was not appropriate because the peaks of this condition were not completely resolved. This problem was solved by using a gradient program on a Synergy Polar-RP $(250 \mathrm{~mm} \times 4.6 \mathrm{~mm}, 4 \mu \mathrm{m})$ column and the mobile phase consisted of mixture of acetonitrile-water. To evaluate the mobile phase, different ratios of acetonitrile-water were tested with respect to optimal peak sharpness, separation efficiency and short elution time. The acetonitrile-water gradient elution $[90+10(0 \mathrm{~min})$ up to $60+40(35 \mathrm{~min})$, equilibrated at initial conditions for $15 \mathrm{~min}$ ] at $210 \mathrm{~nm}$ showed the best conditions with respect to the analysis of the pesticides investigated. The HPLC chromatogram obtained of a pesticide standard solution is illustrated in Fig. 1.

Matrix components can provide variation in the detector response to pesticides. Therefore, matrix effects were evaluated by comparing the responses (areas) of know concentrations of working standards prepared in acetonitrile (S) with those prepared in blank stem extract (E). Differences observed in response could thus be attributed to the effect of sample matrix on the chromatographic system. The ratio E/S is defined as matrix effect. The absence of matrix effect is indicated by a value of 1.0, i.e., the response in solvent and in the extract is the same. A value of $>1.0$ indicates a response enhancement and a value of $<1.0$ indicates a response decrease (Freitas \& Lanças 2009). Matrix effects of 1.9, 2.4 and 1.25 were observed for difenoconazole, carbofuran and thiophanatemethyl, respectively, which represent an increase in the chromatographic response in matrix presence. For spirodiclofen and $\beta$-cifluthrin, no matrix effect was detected, once the value was 1.02 .

In MSPD, selection of a suitable sorbent/solvent system is determined by the polarity of the analyte and the nature of the matrix. The isolation of polar analytes is achieved using polar sorbents, while the isolation of non-polar analytes requires non-polar sorbents (Nollet and Rathore 2010). Tests were performed to evaluate the efficiency of extraction of the pesticides from the sample matrix, using cyclohexane:acetone $(4: 1, \mathrm{v} / \mathrm{v})$ mixture with silica gel, Florisil, neutral alumina, and $\mathrm{C}_{18}$-bonded silica as sorbents. The extraction method proposed was based on our previous MSPD procedures (Aquino and Navickiene 2009; Aquino et al. 2010; Fróes et al. 2013). The solvent used for elution of the pesticides from the column should be selective and efficient. The recoveries of the pesticides in the extracts were calculated by peak area comparisons using solutions of known concentration. The results showed that at the spiked level of $1.0 \mu \mathrm{g} / \mathrm{g}$, recovery values using $\mathrm{C}_{18}$-bonded silica and with cyclohexane:acetone (4:1, v/v) mixture
Fig. 1 HPLC/UV-DAD chromatogram of pesticide standard solution at a concentration level of $0.5 \mu \mathrm{g} / \mathrm{g}$. The pesticide peaks are as follows: 1 tiophanate-methyl (21.5 $\mathrm{min}), 2$ carbofuran (24.3 min), 3 difenoconazole (25.1 min), 4 spirodiclofen (28.6 min) and $5 \beta$-cyfluthrin (31.2 min)

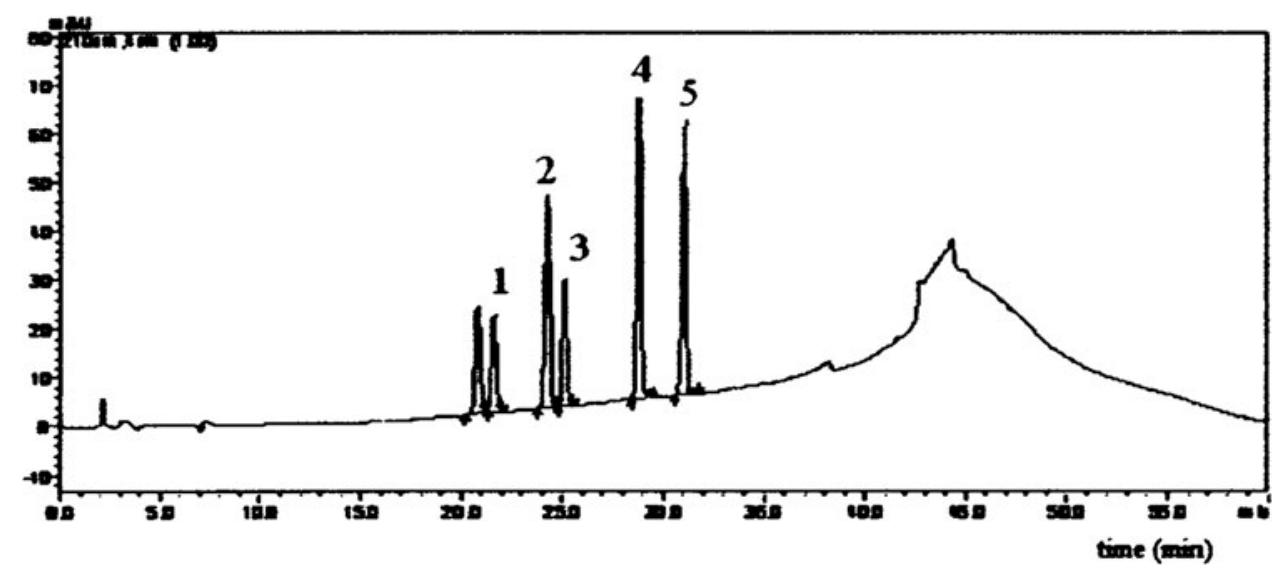


elution were below the range reported in the literature (70 \%-120\%) for difenoconazole (44\%), $\beta$-cyfluthrin (42\%), carbofuran (35\%), thiophanate-methyl (51\%) and spirodiclofen (45\%) (SANCO 2012). When using silica gel as sorbent, the recovery was in the range between $55 \%$ and $77 \%$. On the other hand, the use of the neutral alumina as adsorbent provided recovery values of $44 \%-68 \%$ for the pesticides studied. However, the recovery values using Florisil were in the range $72 \%-78 \%$, showing that this was the most effective sorbent for extraction of the pesticides. On the other hand, different volumes (20, 30 and $40 \mathrm{~mL})$ of cyclohexane:acetone $(4: 1, \mathrm{v} / \mathrm{v})$ mixture were used, but better recoveries were not obtained by using larger volumes. Twenty milliliters of cyclohexane:acetone $(4: 1, \mathrm{v} / \mathrm{v})$ yielded effective recoveries for the pesticides. Based on these results, $20 \mathrm{~mL}$ of cyclohexane:acetone (4:1, $\mathrm{v} / \mathrm{v})$ mixture was selected for all further work. In the MSPD method development, the ratio of stem and sorbent was initially optimized. The optimal ratio of stem and sorbent was found to be $2 \mathrm{~g}$ of stem and $1.6 \mathrm{~g}$ of sorbent. However, the increase in the sorbent quantity did not improve the results. Table 1 provides the percentage recoveries obtained for the different MSPD sorbent/solvent systems.

After optimization of the MSPD procedure, the technique was validated in order to demonstrate its reliability (SANCO 2012). The concentration levels evaluated in this study were $0.05,0.5,1.0$, and $2.0 \mu \mathrm{g} / \mathrm{g}$. Three replicate samples of stem were extracted using Florisil as solid dispersion sorbent. Average recoveries obtained for carbofuran, difenoconazole, spirodiclofen, $\beta$-cifluthrin, and thiophanate-methyl ranged from $65.0 \%$ to $114.3 \%$, with relative standard deviations between $1.2 \%$ and $19.2 \%$ (Table 2). These values indicate that the method is accurate and precise for the quantification of pesticide residues in stem of coconut palm. Linearity was calculated from the

Table 1 Influence of different solid-phase sorbent on recovery percentage using dichloromethane as eluting solvent on pesticide recovery in the MSPD procedure

\begin{tabular}{lllll}
\hline Pesticide & \multicolumn{4}{l}{ Recovery average $(\%)$} \\
\cline { 2 - 5 } & \multicolumn{3}{l}{ Cyclohexane:acetone $(4: 1, \mathrm{v} / \mathrm{v}, 20 \mathrm{~mL})$} \\
\cline { 2 - 5 } & $\begin{array}{l}\text { Silica } \\
\text { gel } \\
(1.6 \mathrm{~g})\end{array}$ & $\begin{array}{l}\mathrm{C}_{18} \text {-bonded } \\
\text { silica }\end{array}$ & Florisil & $\begin{array}{l}\text { Neutral } \\
\text { alumina }\end{array}$ \\
\hline Carbofuran & 77 & 35 & 74 & 68 \\
$\beta$-Cyfluthrin & 69 & 42 & 78 & 57 \\
$\begin{array}{l}\text { Difenoconazole } \\
\text { Spirodiclofen }\end{array}$ & 71 & 44 & 75 & 44 \\
$\begin{array}{l}\text { Thiophanate- } \\
\text { methyl }\end{array}$ & 52 & 45 & 72 & 52 \\
\end{tabular}

Stem of coconut palm sample fortified at $1.0 \mu \mathrm{g} / \mathrm{g}$
Table 2 Percentage recoveries and relative standard deviations for the pesticides studied obtained using the MSPD procedure applied to the fortified stem of coconut palm

\begin{tabular}{lll}
\hline Pesticide & Spiked level $(\mu \mathrm{g} / \mathrm{g})$ & $\begin{array}{l}\% \text { Recovery }(\mathrm{n}=3) \\
(\% \text { mean; } \% \text { RSD })\end{array}$ \\
& & $\begin{array}{l}\text { Stem }(2 \mathrm{~g})+\text { Florisil } \\
(1.6 \mathrm{~g})+\text { cyclohexane: } \\
\text { acetone }(4: 1, \mathrm{v} / \mathrm{v}, 20 \mathrm{~mL})\end{array}$ \\
\hline Carbofuran & 0.05 & $103.5 ; 6.1$ \\
& 0.5 & $89.7 ; 9.5$ \\
& 1.0 & $114.3 ; 10.9$ \\
$\beta-C y f l u t h r i n$ & 2.0 & $100.3 ; 8.6$ \\
& 0.5 & $75.0 ; 13.4$ \\
& 1.0 & $88.4 ; 11.0$ \\
Difenoconazole & 2.0 & $87.0 ; 14.6$ \\
& 0.05 & $65.0 ; 11.5$ \\
& 0.5 & $80.3 ; 13.2$ \\
& 1.0 & $82.6 ; 12.5$ \\
Spirodiclofen & 2.0 & $100 ; 16.5$ \\
& 0.05 & $94.6 ; 19.2$ \\
methyl & 0.5 & $77.0 ; 14.1$ \\
& 1.0 & $84.6 ; 13.5$ \\
& 2.0 & $88.0 ; 15.9$ \\
& 0.5 & $70.0 ; 10.6$ \\
& 1.0 & $84.5 ; 9.3$ \\
& 2.0 & $71.0 ; 1.2$ \\
\hline
\end{tabular}

analytical curves obtained using stem sample solutions containing pesticide concentrations of $0.04,0.1,0.2,0.4$, 1.0, 2.0, 10, 15 and $20 \mu \mathrm{g} / \mathrm{mL}$, analyzed in triplicate. Good linearity was obtained for all pesticides, with coefficients of determination greater than 0.9974. Detection and quantification limits ranged from 0.02 to $0.03 \mu \mathrm{g} / \mathrm{g}$, and from 0.05 to $0.1 \mu \mathrm{g} / \mathrm{g}$, respectively. The repeatability of the chromatographic method was determined by replicate analyses of a standard solution at $0.5 \mu \mathrm{g} / \mathrm{g}$ during different days. The repeatability of the extraction step was estimated analyzing four aliquots of stem sample each day, and during four days. RSD values within and between days were below $8 \%$ and $15 \%$, respectively, which is considered to be acceptable given the difficulty of analyzing these compounds in stem samples (Table 2).

In conclusion, the proposed MSPD method, with analysis by HPLC/UV-DAD, has been shown to be efficient for the extraction of carbofuran, difenoconazole, spirodiclofen, $\beta$-cifluthrin, and thiophanate-methyl residues from stem of coconut palm. The method uses a Florisil-based MSPD column and cyclohexane:acetone $(4: 1, \mathrm{v} / \mathrm{v})$ as elution solvent. The RSD of the pesticides were lower than $20 \%$, and the recovery ranged from $65.0 \%$ to $114.3 \%$. 
Acknowledgments The authors wish to thank MCTI/CNPq (process number 620247/2008-8) for financial support of this study. JAF also thanks CAPES for provision of a research fellowship.

\section{References}

Al-Samarrie AI, Akela AA (2011) Distribution of injected pesticides in data palm trees. Agric Biol J N Am 12:1416-1426

Aquino A, Navickiene S (2009) MSPD procedure for determination of carbofuran, pyrimethanil and tetraconazole residues in banana by GC-MS. Chromatographia 70:1265-1269

Aquino A, Bezerra DSS, Navickiene S (2010) A matrix solid-phase dispersion method for the extraction of seven pesticides from mango and papaya. J Chromatogr Sci 48:750-754

Barker SA (2007) Matrix solid-phase dispersion (MSPD). J Biochem Biophys Meth 70:151-162

Bliesner DM (2006) Validating chromatographic methods-a practical guide. Wiley, New Jersey

Capriotti AL, Cavaliere C, Giansanti P, Gubbiotti R (2010) A recent developments in matrix solid-dispersion extraction. J Chromatogr A 1217:2521-2532

Fontes HR, Procopio SO, Cargnelutti Filho A, Ferreira JMS, Fernandes MF (2009) Efficacy of the herbicide MSMA in eradicating coconut trees infected with stem-bleeding. Planta Daninha 27:859-865
Freitas SS, Lanças FM (2009) Matrix effects observed during pesticides residue analysis in fruits by GC. J Sep Sci 32:3698-3705

Fróes MBR, Santos LFS, Navickiene S (2013) Multi-residue determination of pesticides Açaí tropical fruit (Euterpe oleracea) by matrix solid-phase dispersion combined with liquid chromatography. Food Anal Meth 6:328-333

Garcia-Lopes M, Canosa P, Rodrígues J (2008) Trends and recent applications on matrix solid-phase dispersion. Anal Bioanal Chem 391:963-974

Lecomte P, Darrieutort G (2007) Evaluation of trunk injection technique to control grapevine wood deseases. Phytopathol Mediterr 46:50-57

Mohan C, Radhakrishnan Nair CP, Nampoothiri CK, Rajan P (2010) Leaf-eating caterpillar (Opisina arenosella) induced yield loss in coconut palm. Int J Trop Insect Sci 30:132-137

Nollet LML, Rathore HS (2010) Handbook of pesticides-methods of pesticide residues analysis. CRC Press, Boca Raton

Percival GC, Boyle S (2005) Evaluation of microcapsule trunk injections for the control of apple scab and powdery mildew. Ann Appl Biol 147:119-127

Ranasinghe CS, Fernando WPKK, Zoneer SMM, Mubarak HM (2003) Analysis of residue levels in kernel and nut water of coconut palms injected with monocrotophos. J Natl Sci Found Sri 31:431-436

SANCO No.12495/2011 (2012) Method validation and quality control procedures for pesticide residues analysis in food and feed. The European Commission, United Kingdom 